\section{Acknowledgments.}

Financial support. No financial support was provided relevant to this article.

Conflicts of interest. The author reports no conflicts of interest relevant to this article.

\section{References}

1. Schreier H, Erdos G, Reimer K, et al. Molecular effects of povidone-iodine on relevant microorganisms: an electron-microscopic and biochemical study. Dermatology 1997;195 suppl 2:S111-S116.

2. Sriwilaijaroen N, Wilairat $\mathrm{P}$, Hiramatsu $\mathrm{H}$, et al. Mechanisms of the action of povidone-iodine against human and avian influenza A viruses: its effects on hemagglutination and sialidase activities. Virol J 2009;6:124-129.

3. Eggers M. Infectious disease management and control with povidone iodine. Infect Dis Ther 2019;8:581-593.

4. Pandemic influenza preparedness action plan of the Japanese government. Japan Ministry of Health, Labour and Welfare website. http:// www.mhlw.go.jp/english/topics/influenza/dl/pandemic02.pdf. Published 2007. Accessed March 2018.
5. Eggers M, Koburger-Janssen T, Eickmann M, et al. In vitro bactericidal and virucidal efficacy of povidone-iodine gargle/mouthwash against respiratory and oral tract pathogens. Infect Dis Ther 2018;7:249-259.

6. Kariwa H, Fujii N, Takashima I. Inactivation of SARS coronavirus by means of povidone-iodine, physical conditions and chemical reagents. Dermatology 2006;212 suppl 1:S119-S123.

7. Ito $\mathrm{H}$, Ito $\mathrm{T}$, Hikida $\mathrm{M}$, et al. Outbreak of highly pathogenic avian influenza in Japan and anti-influenza virus activity of povidone-iodine products. Dermatology 2006;212 suppl 1:S115-S118.

8. Frank S, Capriotti J, Brown SM, Tessema B. Povidone-iodine use in sinonasal and oral cavities: a review of safety in the COVID-19 Era. Ear Nose Throat J 2020;99:586-593.

9. Bidra AS, Pelletier JS, Westover JB, Frank S, Brown SM, Tessema B. Rapid in-vitro inactivation of severe acute respiratory syndrome coronavirus 2 (SARS-CoV-2) using povidone-iodine oral antiseptic rinse. J Prosthodont 2020;29:529-533.

10. Sanders JM, Monogue ML, Jodlowski TZ, et al. Pharmacologic treatments for coronavirus disease 2019 (COVID-19): a review. JAMA 2020;323: $1824-1836$.

\title{
Reducing hospital-acquired infections in a regional health system
}

\author{
Keith L. Grant APRN, MSN, RN, CIC ${ }^{1}$, Dora E. Wiskirchen PharmD, BCPS, BCIDP², Ulysses Wu MD², \\ Michael R. Grey MD, MPH ${ }^{2}$ and Pracha P. Eamranond MD, MPH ${ }^{3}$ (C) \\ ${ }^{1}$ Hartford Healthcare, Hartford, Connecticut, ${ }^{2}$ Saint Francis Hospital \& Medical Center, Hartford, Connecticut and ${ }^{3}$ Brigham \& Women's Hospital, Harvard Medical \\ School, Boston, Massachusetts
}

To the Editor-Hospital-acquired or nosocomial infections are infections that patients develop during the course of their hospitalization. ${ }^{1}$ Patients who develop HAIs are usually infected exogenously when exposed to a healthcare facility, procedure, staff, visitors, and/or other patients such that "prevention of hospital-acquired infection is central to providing safe and highquality health care." ${ }^{2}$ An estimated 1.7 million patients in the United States are diagnosed with a HAIs annually. Nearly $5.8 \%$ of those patients, $\sim 100,000$ individuals, will die. ${ }^{3}$ The annual national cost of HAIs is between $\sim \$ 28$ and $\sim 45$ billion in the United States. ${ }^{4}$ Most of the cost of HAIs stems from increased hospital stays and use of medical resources. ${ }^{5}$ However, the cost of reducing HAIs can also be very expensive and requires investment in staff, technology, and other resources. Many studies on improving hand hygiene to reduce HAIs have been published ${ }^{6-9}$; however, many other important interventions have been studied, particularly those that are more systematic and involve multiple stakeholders. ${ }^{10}$ Here, we summarize the successful efforts of a regional health system to reduce HAIs without increasing operational costs.

Author for correspondence: Pracha P. Eamranond, E-mail: peamranond@bwh. harvard.edu

Cite this article: Grant KL, et al. (2021). Reducing hospital-acquired infections in a regional health system. Infection Control \& Hospital Epidemiology, 42: 1542-1544, https://doi.org/10.1017/ice.2020.1347

\section{Methods}

In our regional health system, we sought to create an intervention that provides high-quality, safe, and cost-effective health care across multiple healthcare facilities. We identified the reduction of the HAI standardized international ratio (SIR) as a primary measure of our goal of providing safe health care to our New England population. The Trinity Health of New England (THONE) healthcare system spans Connecticut to Massachusetts, with 5 hospitals and multiple outpatient sites across all major subspecialties. In this study, we included all of the HAIs that the National Healthcare Safety Network (NHSN) mandates that our health system tracks.

Our primary goal was to reduce the SIR to $<1.0$ within 3 years. To achieve this goal, the infection control team performed a literature review for infection prevention best practice and performed a gap analysis of current practices versus best practices. The challenges identified included a lack of standardized best practices and compliance with current policies. To address these opportunities, the hospital focused on some key areas of infection discussed here.

\section{Surveillance}

The primary goal of the new surveillance system was to provide quality and timely data in accordance with National Healthcare Safety Network (NHSN). The secondary goal was to help hospital staff appreciate the process of surveillance and enhance the use of data to drive change. A dashboard was created that would contain updated HAI unit data that would be accessible to all hospital

(c) The Author(s), 2021. Published by Cambridge University Press on behalf of The Society for Healthcare Epidemiology of America. This is an Open Access article, distributed under the terms of the Creative Commons Attribution licence (http://creativecommons.org/licenses/by/4.0/), which permits unrestricted re-use, distribution, and reproduction in any medium, provided the original work is properly cited. 


\begin{tabular}{||l|r|r|r|r|}
\hline \multicolumn{5}{|c|}{ HAI } \\
\hline \multicolumn{1}{|c|}{ Metric } & Numerator & Adj Numerator & Denominator & \multicolumn{1}{c|}{ Rate } \\
CAUTI & 18 & 18.0 & 14.0 & 1.284 \\
CLABSI & 9 & 9.0 & 10.8 & 0.831 \\
MRSA & 3 & 3.0 & 6.0 & 0.502 \\
SSI & 7 & 7.0 & 7.2 & 0.973 \\
CDI & 55 & 55.0 & 81.1 & 0.678 \\
Grand total & 92 & 92.0 & 119.1 & 0.772 \\
\hline
\end{tabular}

\begin{tabular}{|c|c|c|c|c|}
\hline \multicolumn{5}{|c|}{ HAI } \\
\hline Metric & Numerator & Adj Numerator & Denominator & Rate \\
\hline CAUTI & 4 & 4.0 & 12.9 & 0.311 \\
\hline CLABSI & 4 & 4.0 & 10.5 & 0.380 \\
\hline MRSA & 8 & 8.0 & 6.9 & 1.162 \\
\hline sSI & 9 & 9.0 & 6.9 & 1.305 \\
\hline CDI & 26 & 26.0 & 70.5 & 0.369 \\
\hline Grand total & 51 & 51.0 & 107.6 & 0.474 \\
\hline
\end{tabular}

Fig. 1. Hospital-acquired infection (HAI) standardized infection ratio (SIR) during the preintervention period (calendar year 2018) and the postintervention period (calendar year 2019). Note. CAUTI, catheter-associated urinary tract infection; CLABSI, central-line-associated bloodstream infection; MRSA, methicillin-resistant Staphylococcus aureus bacteremia; SSI, surgical site infection; CDI, Clostridium difficile infection. employees and would provide the unit-based surveyors the means to monitor their data independent of the infection prevention department.

\section{Prevention}

A best-practice bundle across the region was implemented in December 2018. Because many hand hygiene compliance protocols have proven effective historically, ${ }^{6-9}$ a hand hygiene compliance program was implemented as an additional intervention. Also, the program was redesigned to allow individual units to decide how they would improve compliance metrics and respond to negative trending. Thus, the staff could take ownership of patient care and could more directly invest in the efforts of by their unit.

Environmental cleaning was identified as another opportunity for improvement. An environmental cleaning audit revealed $<45 \%$ compliance when the program was introduced. In 2019, a $>40 \%$ increase in the proper cleaning of high-touch areas was achieved. Lastly, the hospitals collaborated with the information technology team to implement processes that would automatically place an isolation order.

\section{Early and accurate diagnosis}

Another opportunity revealed by the initial analysis was the number of hospital-onset infections that occurred due to timing of testing. The staff had a knowledge deficit regarding the importance of early detection and treatment of infections. The hospitals addressed this deficit by providing education and clinical guidance through algorithms in the hospital computer system. Providers were educated through computer-based training modules, educational sessions, and one-on-one meetings. Infection prevention staff worked with the infectious disease department to create evidence-based diagnostic tools such as algorithms for diagnosing UTI and a workflow for the proper management of acute diarrhea. This approach could be helpful in decreasing hospital-onset CDI detected after 4 days with symptoms present at time of admission.

\section{Results}

After regional standardization of infection prevention interventions, the SIR decreased from a baseline of 0.772 in calendar year 2018 to 0.474 in calendar year 2019 ( $P<.05 \chi^{2}$ test) (Fig. 1$)$. Reductions in infection rates were observed for catheter-associated urinary tract infection (CAUTI), central-line-associated bloodstream infection (CLABSI), and Clostridium difficile infection (CDI), whereas increases were observed for methicillin-resistant Staphylococcus aureus (MRSA) bacteremia and surgical site infection (SSI).

\section{Discussion}

After regional standardization of best-practice bundles, there was a significant decline in HAIs across all hospitals within our regional healthcare system. In 2014, we started our program with the introduction of a dynamic antimicrobial stewardship based on the Centers for Disease Control and Prevention (CDC) tool kit. The program was led by the chief of infectious disease, the director of infection prevention, and the stewardship pharmacist. All 3 departments collaborated effectively to create policies that would influence best practice. We focused on reducing antibiotic use through education, policy change, and formulary restrictions. We recognize this multipronged approach as the pillar of our success, and we cannot overstate its importance. In fact, the program's entire success is based on the multiple relationships and culture that we have created on this journey. Although many different models exist to reduce HAIs, the best-practice bundle described here was implemented without any major additional cost or capital purchases in an urban hospital managing a large, disproportionate-share, patient population. This team-based, multipronged effort can likely be implemented reliably in other hospital settings.

\section{Acknowledgments.}

Financial support. No financial support was provided relevant to this article.

Conflicts of interest. All authors report no conflicts of interest relevant to this article. 


\section{References}

1. Horan TC, Andrus M, Dudeck MA. CDC/NHSN surveillance definition of healthcare-associated infection and criteria for specific types of infections in the acute care setting. Am J Infect Control 2008;36:309-332.

2. Murni IK, Duke T, Kinney S, Daley AJ, Soenarto Y. Reducing hospitalacquired infections and improving the rational use of antibiotics in a developing country: an effectiveness study. Arch Dis Childhood 2014;100:454-459.

3. Klevens JR. Edwards CL, Richards Jr TC, et al. Estimating healthcareassociated infections and deaths in US hospitals. Public Health Rep 2007;122:160-166.

4. Scott R. The direct medical costs of health care-associated infections in US hospitals and the benefits of prevention. Centers for Disease Control and Prevention website. http://www.cdc.gov/HAI/pdfs/hai/Scott_CostPaper.pdf. Accessed July 19, 2019.
5. Graves N, Halton K, Jarvis W. Economics and Preventing HealthcareAcquired Infection. New York: Springer; 2009.

6. Pittet D. Compliance with hand disinfection and its impact on hospitalacquired infections. J Hosp Infect 2001;48 supplement A: S40-S46.

7. Curtis L. Prevention of hospital-acquired infections: review of nonpharmacological interventions. J Hosp Infect 2008;69:204-219.

8. Carboneau C, Benge E, Jaco MT, Robinson M. A lean six-sigma team increases hand hygiene compliance and reduces hospital-acquired MRSA infections by 51\%. J Healthcare Qual 2010;32:61-70.

9. Hübner N-O, Hübner C, Kramer A. Impact of health campaign on hand hygiene with alcohol-based hand rubs in a nonclinical setting. $J$ Hosp Infect 2013;83 suppl 1:S23-S28.

10. Wenzel RP, Osterman CA, Hunting KJ, Gwaltney JM. Hospital-acquired infections. I. Surveillance in a university hospital. Am J Epidemiol 1976;103:251-260.

\title{
Illicit drug users, alcoholics, and psychiatric patients: Staphylococcus aureus and methicillin-resistant Staphylococcus aureus colonization on the border between community and healthcare settings
}

\author{
Maíris Alarcão Duarte de Oliveira Silvestre MD, $\mathrm{PhD}^{1}$, Marina Barbosa RN, MSc${ }^{1}$, Nathalia Bibiana Teixeira MD², \\ Danilo Flávio Moraes Riboli MSc², Matheus Cristovam de Souza PhD², Maria de Lourdes Ribeiro de Souza da Cunha PhD² \\ and Carlos Magno Castelo Branco Fortaleza MD, $\mathrm{PhD}^{1}$ (c) \\ ${ }^{1}$ Department of Tropical Diseases, Faculdade de Medicina de Botucatu (Botucatu School of Medicine), Universidade Estadual Paulista (São Paulo State \\ University, UNESP). City of Botucatu, São Paulo State, Brazil and ${ }^{2}$ Department of Microbiology and Immunology, Instituto de Biociências de Botucatu (Botucatu \\ Institute of Biosciences), Universidade Estadual Paulista (São Paulo State University, UNESP). City of Botucatu, São Paulo State, Brazil
}

To the Editor-Even though methicillin-resistant Staphylococcus aureus (MRSA) colonization and infections have been extensively reported among users who inject illicit drugs, ${ }^{1,2}$ studies addressing other illicit drug users (IDUs), ${ }^{3}$ alcoholics and psychiatric patients are scarce. ${ }^{4}$ Those latter groups are of special concern when admitted to acute-care or long-term care facilities. In these settings, MRSA colonization may be a predisposing factor for invasive infection and/or for spread of potentially hazardous clones. ${ }^{5}$ With that in mind, we conducted a survey for asymptomatic colonization with overall Staphylococcus aureus and MRSA among patients from 2 psychiatric care hospitals in Botucatu, inner Brazil. Notably, the use of injection drugs is extremely rare in this country, while there is endemic prevalence of use of inhaled cocaine, crack cocaine and marijuana smoking, and abuse of alcoholic beverages. ${ }^{6}$

The study was conducted a reference hospital for short-term admissions of IDUs and alcoholics (70 beds) and a psychiatric hospital with both short and long-term admissions ( 80 beds). Nasal and oropharyngeal swabs were collected from patients upon admission, except for those in long-term care, who had their swabs

Author for correspondence: Carlos Magno Castelo Branco Fortaleza, E-mail: carlos. fortaleza@unesp.br

Cite this article: Silvestre MADdO, et al. (2021). Illicit drug users, alcoholics, and psychiatric patients: Staphylococcus aureus and methicillin-resistant Staphylococcus aureus colonization on the border between community and healthcare settings. Infection Control \& Hospital Epidemiology, 42: 1544-1546, https://doi.org/10.1017/ ice. 2020.1330 collected during their hospital stay, which often lasted years. Species identification and antimicrobial susceptibility tests followed current microbiology practices. MRSA was characterized by amplification of the mecA gene and typing of the staphylococcal chromosome cassette (SCCmec). Molecular strain typing was performed with smaI- or ApaI-based pulsed-field gel electrophoresis (PFGE). A questionnaire was applied to study subjects in the moment of the collection of swabs, and extensive review of their medical charts was performed. Briefly, we assessed information on demographics, sexual behavior, history of previous incarceration, patterns of use of alcohol and illicit drugs. We also recorded the following data for the year previous to inclusion in our study: admissions to acute-care hospitals, invasive procedures (including surgeries), use of antimicrobials, respiratory infection, and skin or soft-tissue infections. Statistical analysis including univariate and multivariable (Poisson regression) models was performed using SPSS version 20 software (IBM, Armonk, NY). We used a stepwise forward strategy to select variables for the multivariable models, with $P<.10$ as a criteria for both entering and staying in the models.

In total, 220 subjects were included in our study: 138 from the IDU/alcoholics facility and 82 from the psychiatric hospital. Overall S. aureus and MRSA colonization prevalence rates were as follows: (1) IDUs/alcoholics facility, 28.3\% (95\% confidence interval $[\mathrm{CI}], 20.1 \%-36.6 \%)$ for $S$. aureus and $2.9 \%(95 \%$ CI, $0.8 \%-7.3 \%$ ) for MRSA and (2) psychiatric hospital, $24.3 \%$ (95\% CI, $15.6 \%-35.1 \%)$ for S. aureus and $7.3 \%$ (95\% CI,

(c) The Author(s), 2020. Published by Cambridge University Press on behalf of The Society for Healthcare Epidemiology of America This is an Open Access article, distributed under the terms of the Creative Commons Attribution licence (http://creativecommons.org/licenses/by/4.0/), which permits unrestricted re-use, distribution, and reproduction in any medium, provided the original work is properly cited. 